\title{
A Model for Selecting the Most Cost-Effective Pressure Control Device for More Sustainable Water Supply Networks
}

\author{
Irene Fernández García *(D), Daniele Novara and Aonghus Mc Nabola \\ Department of Civil Structural \& Environmental Engineering, Trinity College of Dublin, Dublin D02 PN40, \\ Ireland; novarad@tcd.ie (D.N.); amcnabol@tcd.ie (A.M.N.) \\ * Correspondence: g52fegai@uco.es
}

Received: 14 May 2019; Accepted: 19 June 2019; Published: 21 June 2019

\begin{abstract}
Pressure Reducing Valves (PRV) have been widely used as a device to control pressure at nodes in water distribution networks and thus reduce leakages. However, an energy dissipation takes place during PRV operation. Thus, micro-hydropower turbines and, more precisely, Pump As Turbines (PAT) could be used as both leakage control and energy generating devices, thus contributing to a more sustainable water supply network. Studies providing clear guidelines for the determination of the most cost-effective device (PRV or PAT) analysing a wide database and considering all the costs involved, the water saving and the eventual power generation, have not been carried out to date. A model to determine the most cost-effective device has been developed, taking into account the Net Present Value (NPV). The model has been applied to two case studies: A database with 156 PRVs sites located in the UK; and a rural water supply network in Ireland with three PRVs. The application of the model showed that although the investment cost associated to the PRV installation is lower in the majority of cases, the NPV over the lifespan of the PAT is higher than the NPV associated with the PRV operation. Furthermore, the ratio between the NPV and the water saved over the lifespan of the PAT/PRV also offered higher values (from 6\% to 29\%) for the PAT installation, making PATs a more cost-effective and more sustainable means of pressure control in water distribution networks. Finally, the development of less expensive turbines and/or PATs adapted to work under different flow-head conditions will tip the balance toward the installation of these devices even further.
\end{abstract}

Keywords: pumps as turbines; pressure reducing valves; energy recovery; leakage reduction; water-energy nexus

\section{Introduction}

World water use has risen considerably in recent decades and this growing tendency is likely to continue due to the expected population growth in the coming years [1]. In addition, large cities are increasingly concentrating a higher number of people, leading to water scarcity conditions in many urban areas [2]. One quarter of the largest cities in the world were recently estimated to be water stressed [3]. In Europe, and more specifically in its southern regions, a 24\% decrease in renewable water resources has been detected during the period 1960-2010 [4]. Moreover, world energy consumption is also expected to increase by $28 \%$ in 2040 with respect to 2015 [5]. Therefore, the sustainable use of water and energy resources is currently one of the main concerns worldwide.

Water abstraction and distribution are among the activities in which the water-energy nexus plays an important role. In the European Union, as an example, 8\% of the total energy consumption in 2014 was related to water supply [6]. In addition, it is estimated that 32 billion cubic meters per year (66\% of the treated water) are lost in the water distribution process globally [7]. This is mainly due to the 
ageing infrastructure, the non-optimal design of the water supply systems, and the increase in water stress in urban areas [8]. Different strategies have been proposed to reduce energy consumption from fossil fuels in the water industry sector, by using renewable energy sources [9] or by recovering the excess of heat at the wastewater treatment plant [10], to name a few.

Leakage management can also play a major role in the reduction of energy consumption in the water sector. Thus, pressure control in water distribution networks is one of the most effective measures to reduce leakages because of the direct relation between pressure and leakage rate [11,12]. Hence, Pressure Reducing Valves (PRVs) play an important role in reducing water losses. The determination of the best location and the number of PRVs to install in a network has been widely analysed as an effective measure to decrease leakages. Gupta et al. [11] applied an optimization algorithm to determine the optimal PRVs location in a network, resulting in a leakage reduction of $21 \%$. Fontana et al. [13] used real time control to manage the pressure in a PRV placed in a network inlet. This enabled optimal operation conditions by reducing pressure at nodes and therefore, leakages.

PRVs are a convenient device for reducing leakage. However, the energy dissipation that takes place in a PRV is wasteful of energy resources, and this energy could be recovered by substituting the PRV with a hydropower turbine. Thus, in addition to the reduction of water losses, a certain part of the energy in the network could be recovered, reducing greenhouse gas emissions and making the water supply system more sustainable [14]. Due to the potential of hydropower in these systems, several investigations have focused on the evaluation of the installation of these devices in water networks, showing that up to $40 \%$ of the gross power potential available in a PRV could be recovered by replacing the PRV with a PAT [15]. Other potential locations for installing hydropower turbines, such as break pressure tanks, water storages or water treatment plants, were also evaluated, estimating significant energy generation potential in some locations [16].

The main disadvantage historically associated with hydropower installations in water distribution networks was their lack of cost-effectiveness when the power output capacity is small [17]. The majority of power output capacities in typical PRVs in water distribution networks has been shown to lie in the range 1 to $15 \mathrm{~kW}$ [18]. However, recent developments in new micro-turbines which can operate under low flow/head conditions or new in-line Banki turbines with mobile regulating flap which enable the adaptation of the characteristic curve according to flow or pressure with reasonable high efficiencies may alter the results of these historical assessments which considered traditional turbine types [19-22].

A particular class of micro-turbines consists of pumps working in reverse mode, i.e., Pump As Turbines (PAT). These are devices that can be installed along distribution pipes to reduce pressure at nodes and recover energy [23-25], with significantly reduced investment costs compared to traditional turbines [26]. Optimization techniques have focused on identifying the best PAT location within water distribution networks to reduce leakage and generate energy. Giugni et al. [27] proposed a methodology to determine the optimal PAT location in water distribution networks considering two approaches: The reduction of leakage, and the maximization of energy. The authors demonstrated that the second approach involved higher energy production without decreasing pressure at nodes significantly. Other methodologies have considered the joint optimization of energy generation by means of PATs, leakage reduction and pump operation in order to reduce the energy costs associated with the water network $[25,28]$. The use of PATs as energy recovery devices within irrigation water distribution networks has also been proved feasible, with calculated annual energy recovery of up to $58 \mathrm{MWh}$ and $271 \mathrm{MWh}$ in selected networks $[29,30]$.

The replacement of PRVs with PATs as a measure to generate energy and reduce leakage represents an efficient strategy to improve the sustainability of water supply networks. However, the sometimes small amounts of energy generated by a PAT can be interpreted as not achieving economic viability in some cases, making PRVs more attractive. For example, Fecarotta et al. [25] proposed an optimization procedure to determine the best location and the number of PATs considering both the maximization of the net present value (NPV) and the reduction of leakage. They included the water cost saving by leakage reduction in the estimation of the NPV and the algorithm provided a solution with 16 PATs 
to install on a selected network. However, 10 out of the 16 PATs were considered not economically feasible due to the low power generated. Therefore the authors proposed the installation of PRVs instead of PATs for those sites.

Some investigations have evaluated the replacement of PRVs by PATs as a measure to control pressure and generate energy, also analysing the most convenient element from an economic point of view $[24,31,32]$. However a comprehensive study giving guidelines for the installation of pressure reducing devices (PRV or PAT) for pressure reduction at specific nodes taking into account all the cost involved in both, and the eventual power generation have not been provided to date.

Therefore in this work a model has been developed to aid in choice between PAT and PRV in water distribution networks. The model focuses on the determination of the Net Present Value (NPV) taking into account the total cost associated with the installation of a PRV and a PAT as well as the cost savings associated with the reduction of leakage volume and the energy savings related to the PAT performance. The methodology has been applied to two case studies: The first one included a database with 156 PRVs sites located in Wales and West Midland regions of the UK; while the second case study included a water distribution network with three PRVs currently operating, located in a rural area in Ireland.

\section{Methodology}

\subsection{Problem Approach}

The model proposed in this work took into account all costs involved in the installation of a PRV and a PAT, as well as the sum of the incomes associated with the operation of both devices during their lifespan. Thus, NPV $(€)$, which was previously used to determine the economic feasibility of the installation of PATs [25], was selected in this work to compare both devices:

$$
N P V=-T C+\sum_{t=1}^{L} \frac{C S_{t}}{(1+r)^{t}}
$$

where $T C(€)$ is the total installation cost, $t$ is an index related to year, $L$ is the lifespan of the device considered, PRV or PAT (assumed as 15 years for both elements in this work). CS is the total cost saving at year $t(€)$, and is determined by adding up the water cost saving, WCS, associated with the reduction of leakage volume after installing these devices and the energy cost saving, ECS, obtained by the PAT performance. $r$ is the discount rate. A value of 0.05 for $r$ was assumed in this work [33]. No management costs have been considered since the same cost has been assumed for both installation types.

The total installation cost was determined using Equation (2):

$$
T C=C_{P R D}+C_{H E}+I C
$$

where $C_{P R D}$ is the cost of the pressure reducing device, PRD (PRV or PAT), $C_{H E}$ the cost of the hydraulic elements required in the installation of each pressure reducing device, and IC is the installation cost. The determination of each term in Equation (2) is described in the following sections.

The estimation of WCS was carried out by the calculation of the water saving derived from the installation of a PRV or a PAT. When any of these devices is installed in a water supply network, pressure at nodes decreases and hence the leakage flow is reduced.

When the leakage flow at each pipe is known, this value can be assigned to each node and the discharge coefficient, $c_{i}$, which relates the leakage flow to pressure can be determined according to Equation (3):

$$
q l_{i}=c_{i} \cdot P_{i}^{\beta}
$$


where $q l_{i}$ is the leakage flow at node $i\left(1 \mathrm{~s}^{-1}\right), \beta$ is the emitter exponent which takes into account the pipe material and the shape of the orifice (1.18 has been assumed in this work [34]) and $P_{i}$ is the pressure (m) at node $i$. The coefficient $c_{i}$ was determined by Equation (4):

$$
c_{i}=\alpha \cdot 0.5 \cdot \sum_{j=1}^{K j i} L_{j i}
$$

$\alpha$ is a coefficient $\left(1 \mathrm{~s}^{-1} \mathrm{~m}^{-1-\beta}\right), j$ is an index related to pipe, Kji is the number of pipes connected to node $i$, and $L_{j i}$ is the length of the pipe $j$ connected to node $i(\mathrm{~m})$. The coefficient $\alpha$ was determined using EPANET [35] which enabled the pressure dependent demand analysis. Once the coefficient $\alpha$ was determined, the effects of the performance of a PRD were evaluated in EPANET and WCS was estimated by:

$$
W C S=c_{w} \cdot\left(V l_{0}-V l_{P R D}\right) \cdot n \text { days }
$$

where $c_{w}$ is the water cost $\left(0.3 € \mathrm{~m}^{-3}\right.$ was assumed in this work [25]) and $V l_{0}$ and $V l_{P R D}\left(\mathrm{~m}^{3}\right.$ day $\left.^{-1}\right)$ are the leakage volume in the current situation and after installing the pressure reducing device, respectively. ndays was the number of days of the year. The leakage volume was obtained by applying Equation (6):

$$
V l=\frac{1}{1000} \cdot \sum_{h=1}^{24} Q l_{h} \cdot \Delta h
$$

where the term $1 / 1000$ is used to convert units from $1 \mathrm{~s}^{-1}$ to $\mathrm{m}^{3} \mathrm{~s}^{-1}, Q l_{h}$ is the total leakage flow at time $h$ and $\Delta h(\mathrm{~s})$ is the time in which $Q l_{h}\left(1 \mathrm{~s}^{-1}\right)$ is applied.

However, in most of the cases, the leakage flow of the entire network is the only available data. For these analyses, methodologies to estimate the leakage flow at each node from the total leakage rate have been proposed. In this work, the methodology proposed by Araujo et al. [36] was used. From the current leakage rate, which is usually estimated as a percentage of the minimum total night flow, an iterative process was carried out to determine the value of $c_{i}$ which accomplished Equations (3) and (4) using the software EPANET [35]. This iterative process was required to set the value of $c_{i}$ at each node and thus determine the leakage flow according to the pressure received at each node [37]. After that, two types of demand were applied to the nodes, one associated with the human consumption, while the other was pressure-dependent and related to leakage. Therefore, a genetic algorithm was applied to determine the new demand pattern which, multiplied by the base demand and added up the leakage flow, matched with the actual measured hourly demand of the network. A detailed description of the above methodology can be found in [36]. Once the leakage flow after installing a PRV or a PAT was obtained, the water cost saving was determined by Equation (5).

The procedure to determine the water saving was carried out in MATLAB [38].

As for the energy cost saving, Equation (7) was used to estimate its value:

$$
E C S=\frac{1}{1000} \cdot \text { ndays } \cdot \sum_{h=1}^{24} \rho \cdot g \cdot Q_{P A T, h} \cdot H_{P A T, h} \cdot \eta_{h} \cdot e p
$$

where the term $1 / 1000$ is used to convert units from $\mathrm{W}$ to $\mathrm{kW}, \rho$ is the water density $\left(\mathrm{kg} \mathrm{m}^{-3}\right), g$ the gravity acceleration $\left(\mathrm{m} \mathrm{s}^{-2}\right), Q_{P A T, h}\left(\mathrm{~m}^{3} \mathrm{~s}^{-1}\right)$ and $H_{P A T, h}(\mathrm{~m})$ the flow and head provided by the PAT at time $h$, respectively. $\eta_{h}$ was the efficiency of the PAT and $e p$ the savings from displaced electricity costs $\left(0.17 € \mathrm{kWh}^{-1}\right.$ has been assumed in this work, [39]).

Different methodologies to estimate the friction losses in a PAT have been developed $[40,41]$. A simplified approach similar to the one proposed by [23] was considered in this work. According to [42], the maximum PAT efficiency, i.e., the efficiency of a PAT at the Best Efficiency Point (BEP) is achieved when the flow at the PAT is $75 \%$ of the maximum flow, considering $0 \%$ as the minimum flow 
rate through a PAT and $100 \%$ as the maximum flow at the same speed. Therefore, two considerations were assumed in this work: (1) $Q_{P A T, h}$ was $Q_{B E P}$ when the input flow was higher than $Q_{B E P}$ and $\eta_{h}$ matched with the maximum PAT flow-to-wire efficiency, $\eta_{\max }$, assumed here as $0.65[18,25]$. In this case, the rest of the flow was bypassed; (2) $Q_{P A T, h}$ matched with the input flow when it was lower than $Q_{B E P}$ and the $\eta_{h}$ was determined according to the methodology proposed by [42], in which they evaluated the performance of 113 PATs by characterising the relationship between head and specific speed. The 113 PATs performance database was included in EPANET, to estimate the hydropower potential according to the instant flow and head at a certain site.

A flow chart with a summary of the methodology above described is shown in Figure 1.

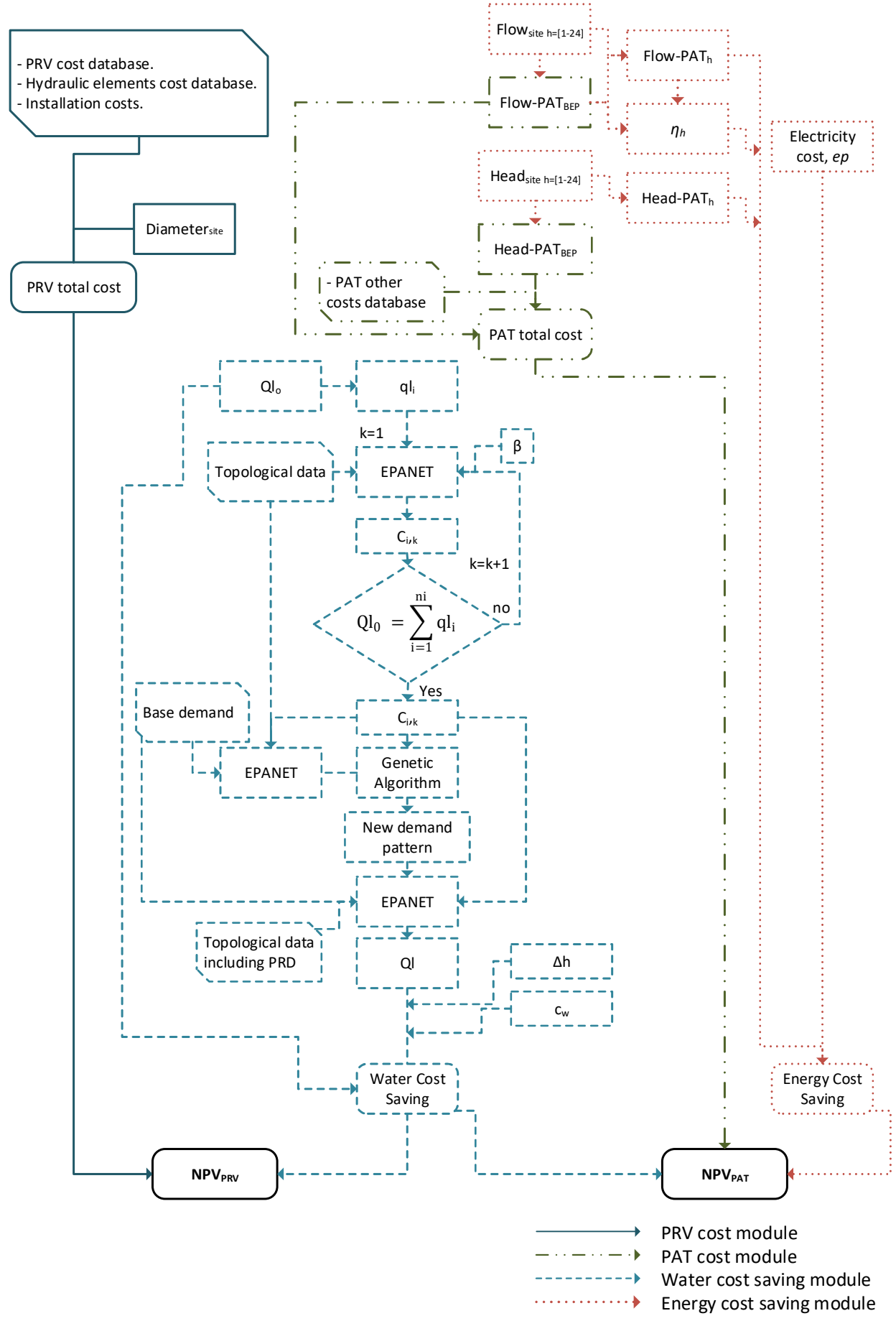

Figure 1. Flow chart of the model to determine the most cost-effective device. 


\subsection{PRV Total Installation Costs}

The installation of a PRV in addition to the valve itself usually requires an upstream isolation valve, a strainer, a downstream isolation valve and an air valve (Figure 2a). In order to select the PRV to be installed in a certain pipe, the flow through it, its diameter and the pressure setting range need to be considered.

a

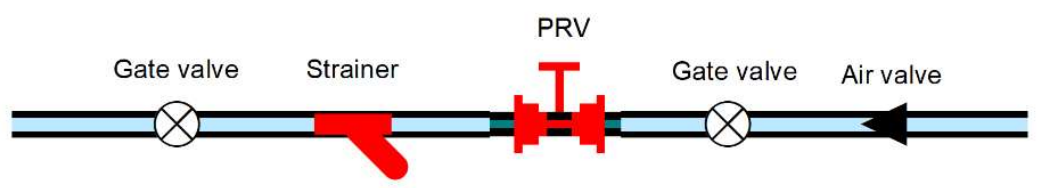

b

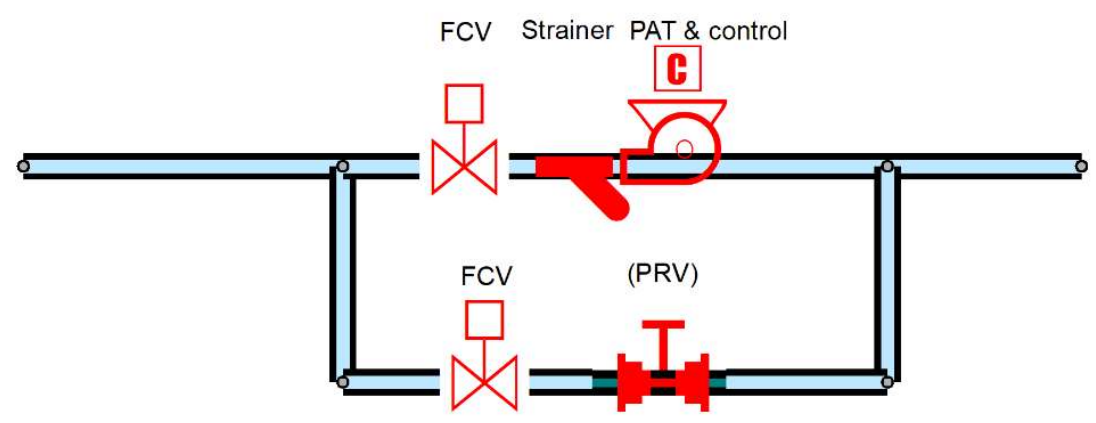

Figure 2. Installation scheme of a Pressure Reducing Valve (PRV) (a) and of a Pump As Turbine (PAT) (b).

Data related to the cost of PRVs from several manufacturers for a wide range of diameters (50, $65,80,100,125,150,200,250,300,400,500$ and $600 \mathrm{~mm}$ ) and for different pressure settings, were collected [43-51]. Likewise, the costs of the hydraulic elements required in the installation of a PRV for different diameters were gathered. Civil works were also considered, and assumed here as the $10 \%$ of the total costs [52].

\subsection{PAT Total Installation Cost}

The cost in the European context of a centrifugal PAT with a connected four-pole asynchronous motor used as a generator can be estimated as function of its nominal flow and head working conditions at the Best Efficiency Point (BEP) through a set of linear correlations [53]:

$$
C_{P A T+\text { gen }}(€)=12,717.29 \cdot Q_{P A T B E P} \sqrt{H_{P A T B E P}}+1038.44
$$

The above equation was determined from a database of 343 commercially available pumps and 286 generators [53]. Only asynchronous induction motors which can efficiently work as generators and are commonly sold as standard prime movers of hydraulic pumps were selected. More specifically, four-pole asynchronous motors have been considered as their moderate nominal speed of about 1500 RPM prevents PATs from reaching an excessive speed under runaway conditions, compared to two-poles units.

Apart from the purchase of the turbine and the generator, the final cost of a typical Micro-Hydropower (MHP) scheme includes additional contributions (see Figure 2b) which can be grouped as follows:

- Civil works and hydraulic equipment, including: 


\author{
a bypass pipe; \\ a Y-strainer; \\ a powerhouse hosting the equipment.
}

a set of actuated or manually operated control and sectioning valves;

a PRV (in certain installations). The necessity of installing this device depends on whether the PAT will operate far from its BEP at a given site, and the capability of the actuated valves to control the pressure received at downstream nodes. If the pressure is too high to be controlled by the actuated control valves, a PRV installed in the bypass is required.

- $\quad$ Electric cabinet and control system

- $\quad$ Grid connection fee

- $\quad$ Commissioning

- $\quad$ Other project costs (including consultancy)

The cost of the above elements in PAT energy recovery installations is unclear, since no comprehensive study has provided a cost breakdown of PAT-based MHP schemes embedded in water infrastructures to date. Some authors have suggested that the contribution given by the purchase of a conventional turbine and generator may account typically for the 35\% [54] up to a maximum of $70 \%$ of the final cost figure of a MHP scheme [18]. However, such figures are not directly applicable to the context of this research since their authors did not consider the use of PATs, which allows for a considerable reduction of the turbine purchase price (5 to 20 times less expensive). In addition, they did not refer specifically to hydropower stations within water distribution networks.

In order to evaluate more accurately the cost of such plants, data from 9 energy recovery schemes in water networks from different countries have been compiled [24,55-57]. All of the selected plants adopted a PAT as a generating device, and had nominal powers ranging from 9 to $120 \mathrm{~kW}$. The location and power rating of all 9 schemes is displayed in Figure 3. According to the available information, it was possible to sub-divide the total cost of the installation into single components:

- $\quad$ turbogenerator alone;

- $\quad$ turbogenerator and control system;

- commissioning;

- $\quad$ civil works and hydraulic equipment;

- $\quad$ grid connection;

- other project costs.

From the purchase price of a PAT and a generator by means of Equation (8), the resulting cost breakdown allowed the realistic quantification of the total expected cost of a PAT-based MHP plant in water infrastructures from its nominal values of flow rate and hydraulic head.

\title{
2.4. Case Studies
}

The first case study consisted of a database with 156 PRVs placed in water infrastructure in Wales and the West Midland regions of the UK (see Figure 4). Information related to average flow, pressure and pipe diameter were collected at those sites [18]. The average flow ranged from $0.21 \mathrm{~s}^{-1}$ to $296.51 \mathrm{~s}^{-1}$ with associated head values of $32 \mathrm{~m}$ and $15 \mathrm{~m}$, respectively. As for diameters, the values were $150 \mathrm{~mm}$, $200 \mathrm{~mm}, 250 \mathrm{~mm}, 300 \mathrm{~mm}$ and $400 \mathrm{~mm}$. 


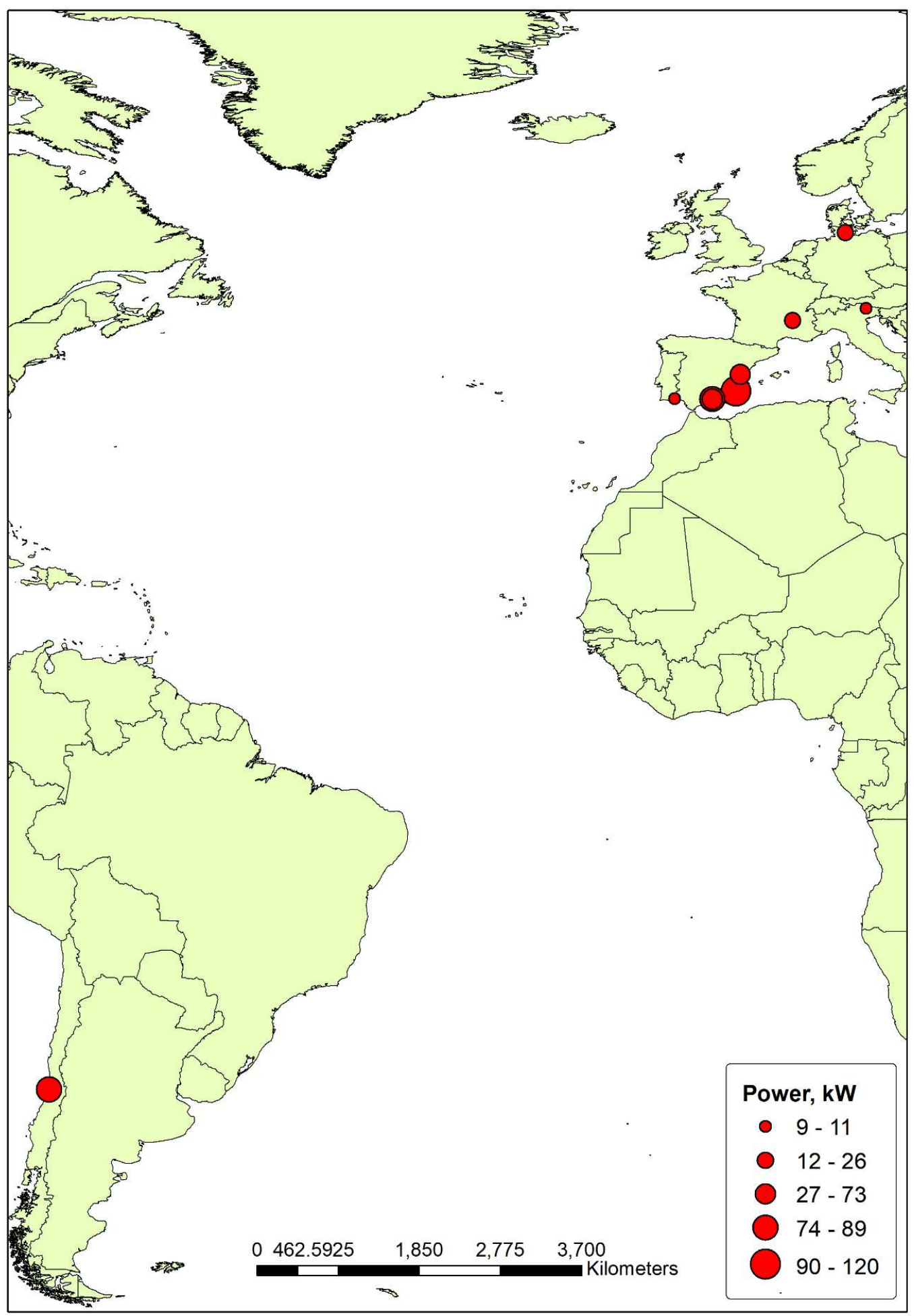

Figure 3. Location of the PAT plants used to estimate the total PAT cost. 


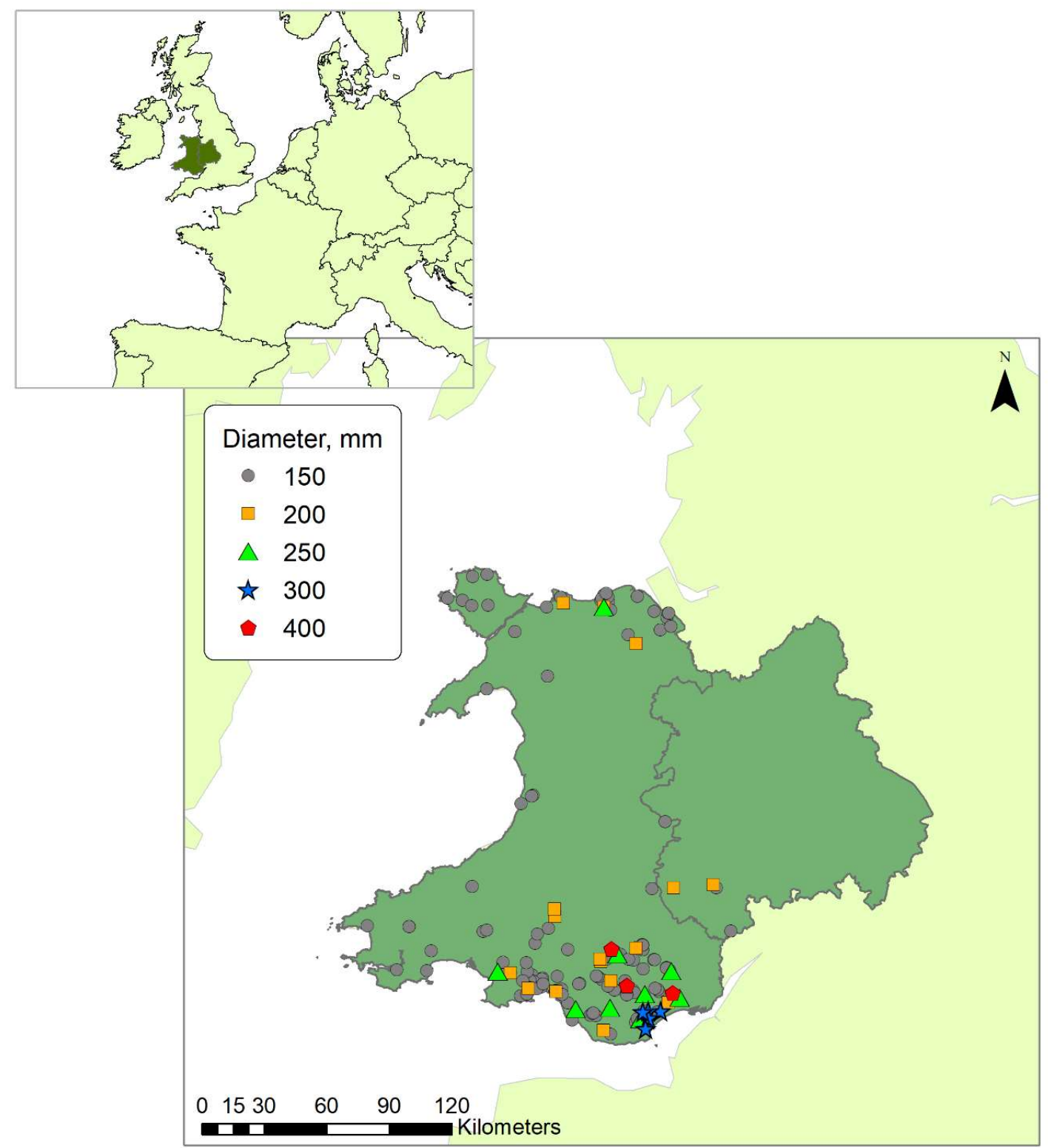

Figure 4. Location of the selected PRV sites.

The second case study focused on Ballinabranna Group Water Scheme (BGWS), a water supply network located in a rural area in Ireland. BGWS is a gravity network which supplies an average demand of $6.161 \mathrm{~s}^{-1}$ to 44 consumption nodes. This network covers an area of almost $54 \mathrm{~km}^{2}$, with diameters ranging from $50 \mathrm{~mm}$ to $150 \mathrm{~mm}$. Three PRVs are currently operating in the network. However, in an analysis to determine the optimum PAT locations in this network, a new potential site was detected [37]. This site showed higher MHP potential than that of the current PRV locations. Hence, the analysis carried out in this work took into account the determination of the NPV in two of the current PRVs and at the proposed additional site (site 3 in Figure 5). 


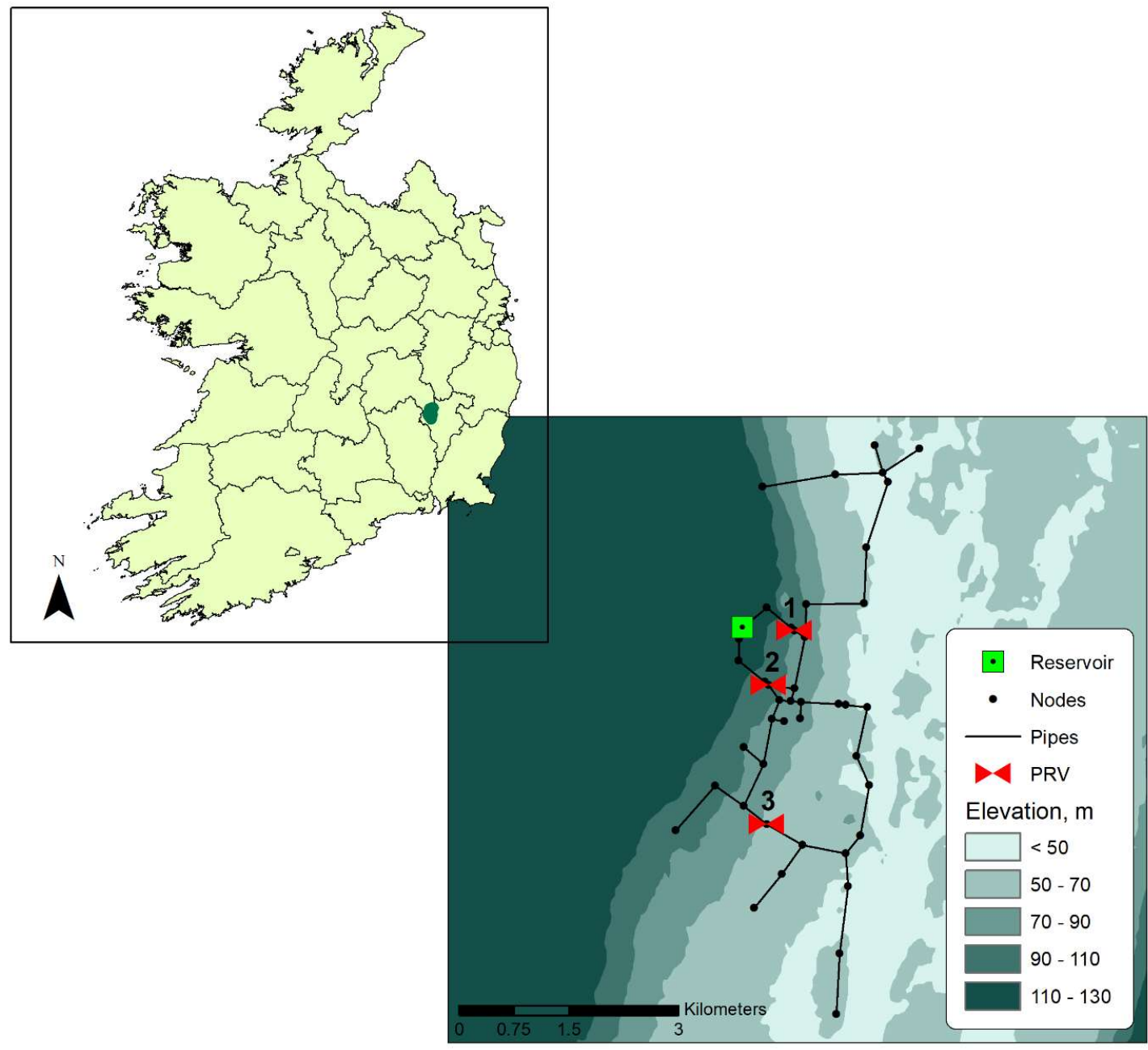

Figure 5. Ballinabranna water supply network layout.

\section{Results}

\subsection{PRV Cost Model}

The cost of 110 PRVs from different manufacturers were collected. The diameter of the selected PRVs ranged from $50 \mathrm{~mm}$ to $600 \mathrm{~mm}$ while the pressure setting range was 6-60 m, 15-60 m, 10-100 m 10-160 m, 14-72 m, 40-120 m, 50-120 m, 10-70 m, 17-86 m and 7-70 m. The average PRV cost was $3516 €$ with a minimum value of $162 €$ for a $50 \mathrm{~mm}$ diameter and a maximum price of $31,765 €$ for a $500 \mathrm{~mm}$ diameter (see Figure 6). As could be expected, the greater the diameter the higher the PRV cost. However, a clear difference between the range of the pressure setting and the PRV cost was not detected. The differences in the PRV cost were mainly related to the different manufacturers who provided the data.

To estimate the total cost, the cost of the two required gate valves, the strainer and the air valve were also considered (Table 1 ). The cost of the two gate valves ranged from $146 €$ to $6370 €$ for diameters of $50 \mathrm{~mm}$ and $600 \mathrm{~mm}$ respectively, whereas the strainer cost varied from $148 €$ to $18,063 €$ for the same diameters. As for the air valve, the cost ranged from $543 €$ for the $50 \mathrm{~mm}$ diameter to $19,286 €$ for the $600 \mathrm{~mm}$ diameter.

These additional costs and the amount of civil works were added to the PRV cost to estimate the total installation cost. Considering an average PRV cost for each diameter according to the values provided by the different manufacturers, the average total cost was $18,762 €$, ranging from $1738 €$ for a $50 \mathrm{~mm}$ diameter pipeline to $72,621 €$ for a $600 \mathrm{~mm}$ diameter (see Figure 7 ). When the minimum PRV 
cost for each diameter was taken into account the average total cost was $16,931 €$, varying from $1099 €$ to $72,621 €$ for diameters of $50 \mathrm{~mm}$ and $600 \mathrm{~mm}$. As for the total cost when the maximum PRV cost for each diameter was selected, the average value was $21,258 €$ ranging from $2520 €$ to $72,621 €$ for diameters of $50 \mathrm{~mm}$ and $600 \mathrm{~mm}$.

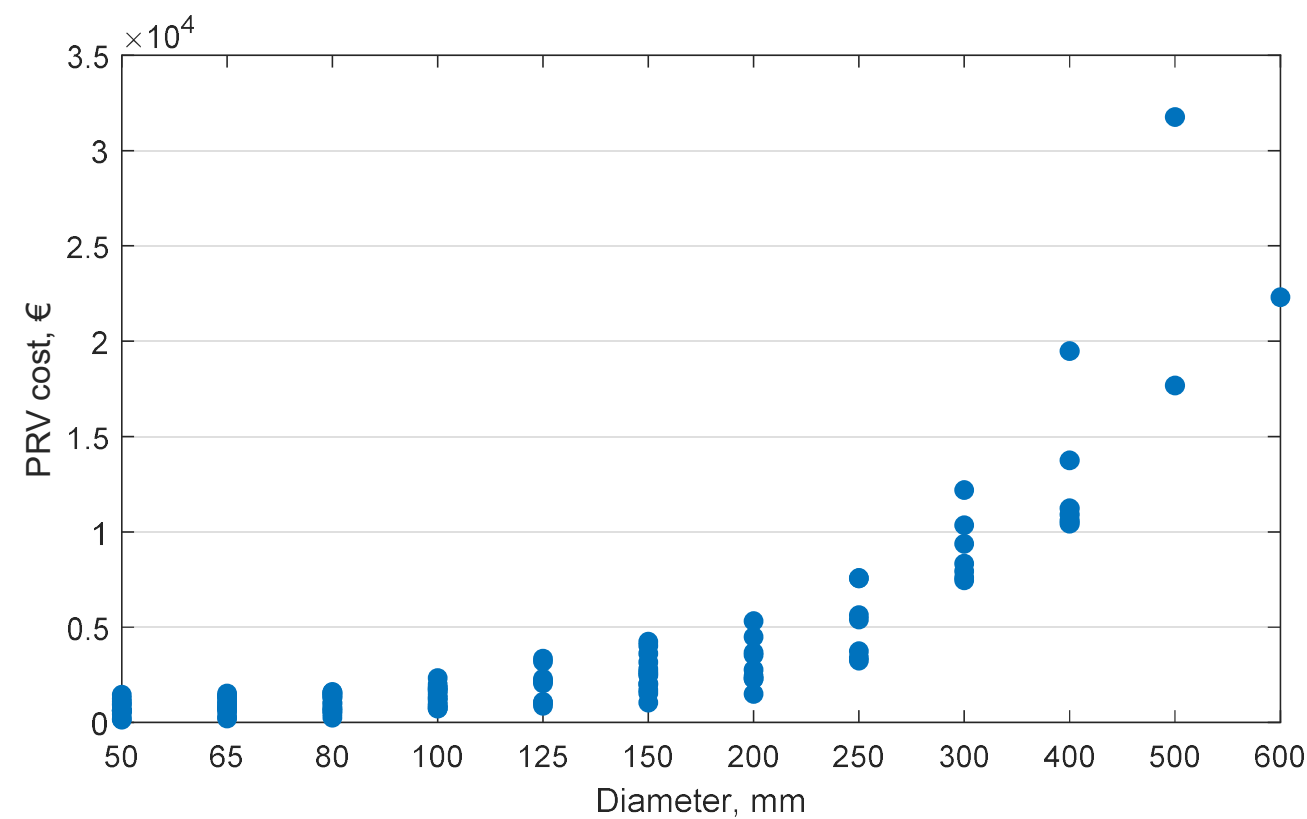

Figure 6. PRV cost for diameters ranging from $50 \mathrm{~mm}$ to $600 \mathrm{~mm}$.

Table 1. Additional costs related to the PRV installation.

\begin{tabular}{ccccccccccccc}
\hline & \multicolumn{10}{c}{ Diameter, $\mathbf{m m}$} \\
\hline & $\mathbf{5 0}$ & $\mathbf{6 5}$ & $\mathbf{8 0}$ & $\mathbf{1 0 0}$ & $\mathbf{1 2 5}$ & $\mathbf{1 5 0}$ & $\mathbf{2 0 0}$ & $\mathbf{2 5 0}$ & $\mathbf{3 0 0}$ & $\mathbf{4 0 0}$ & $\mathbf{5 0 0}$ & $\mathbf{6 0 0}$ \\
\hline Gate valve (2) & 146 & 190 & 218 & 274 & 374 & 514 & 800 & 1216 & 1676 & 2899 & 4462 & 6370 \\
Strainer & 148 & 159 & 208 & 227 & 410 & 391 & 717 & 1377 & 2104 & 5331 & 11,669 & 18,063 \\
Air valve & 543 & 543 & 615 & 854 & 1215 & 1290 & 2520 & 4430 & 4947 & 8953 & 13,624 & 19,286 \\
\hline TOTAL & 837 & 892 & 1041 & 1355 & 1999 & 2195 & 4037 & 7023 & 8727 & 17,183 & 29,756 & 43,719 \\
\hline
\end{tabular}

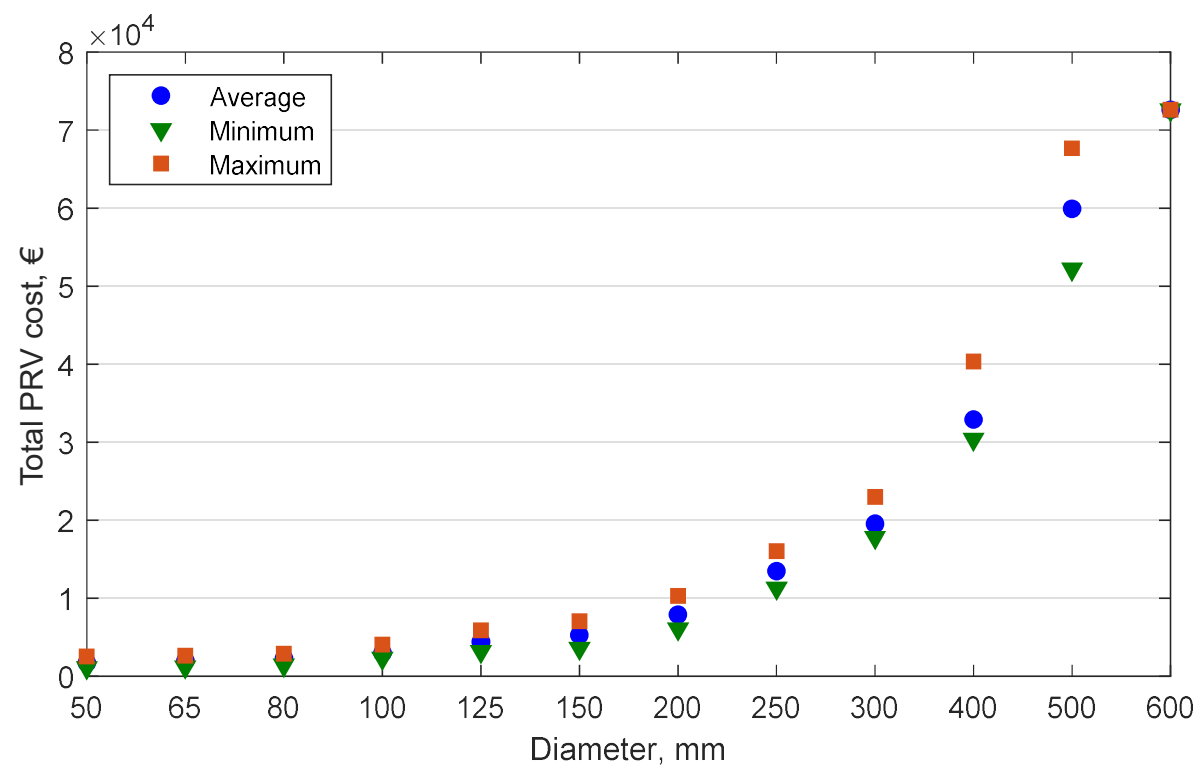

Figure 7. Total PRV cost for diameters ranging from $50 \mathrm{~mm}$ to $600 \mathrm{~mm}$. 


\subsection{PAT Cost Model}

The model developed by [53] was used to determine the PAT cost. A flow range between $0.01 \cdot 10^{-3} \mathrm{~m}^{3} \mathrm{~s}^{-1}$ and $0.4 \mathrm{~m}^{3} \mathrm{~s}^{-1}$ and pressure values varying from $5 \mathrm{~m}$ to $100 \mathrm{~m}$ were considered. The average PAT cost was $18,666 €$, ranging from $1039 €$ for the minimum values of flow and pressure to $51,908 €$ associated with a flow of $0.4 \mathrm{~m}^{3} \mathrm{~s}^{-1}$ and a pressure of $100 \mathrm{~m}$ (see Figure 8 ).

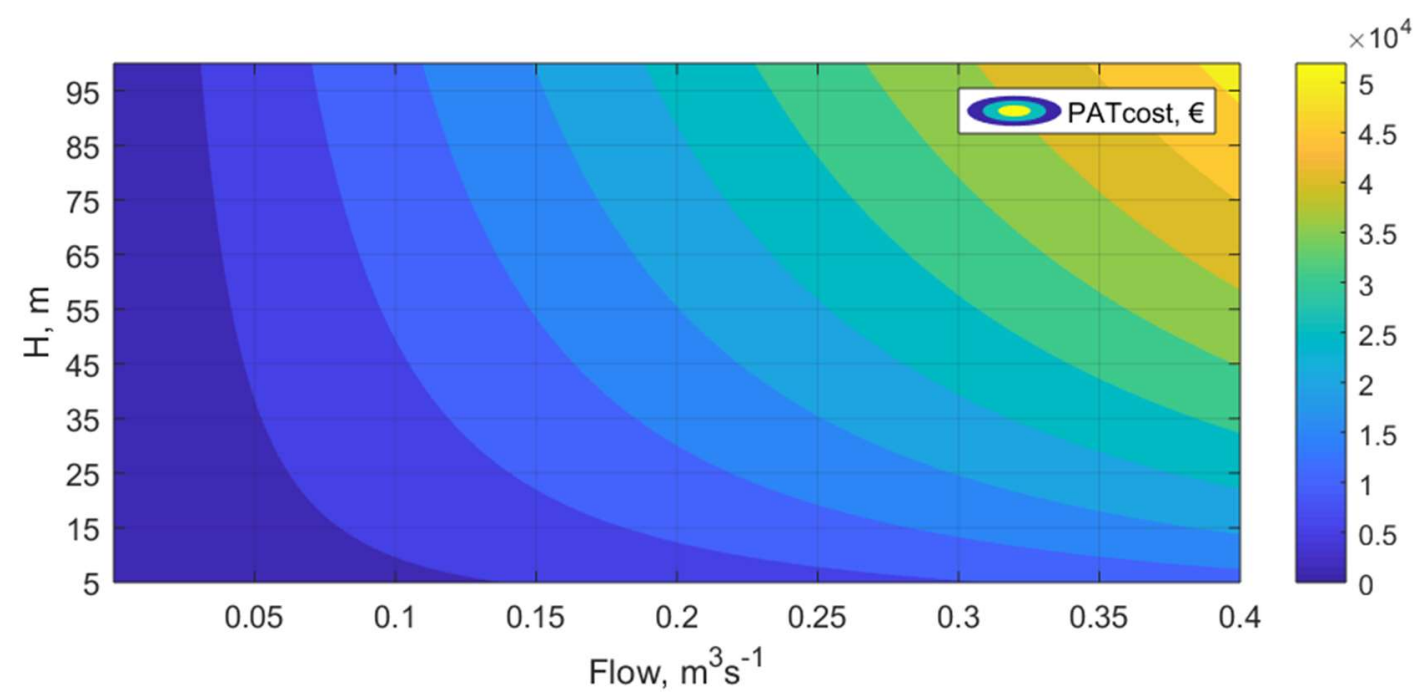

Figure 8. PAT cost according to flow and head.

The analysis of the cost components from the 9 evaluated PAT schemes according to the categories listed in Section 2.3, did not lead to any identifiable trends according to the nominal power of the scheme. Instead, it is reasonable to assume that a number of site-specific conditions (e.g., amount of civil works required, distance from the electric grid, and effectiveness of the design) resulted in varied percentages of each analysed cost category. The overall results of the analysis are shown in Figure 9, where the vertical error bars indicate the minimum and maximum percentages for each cost category.

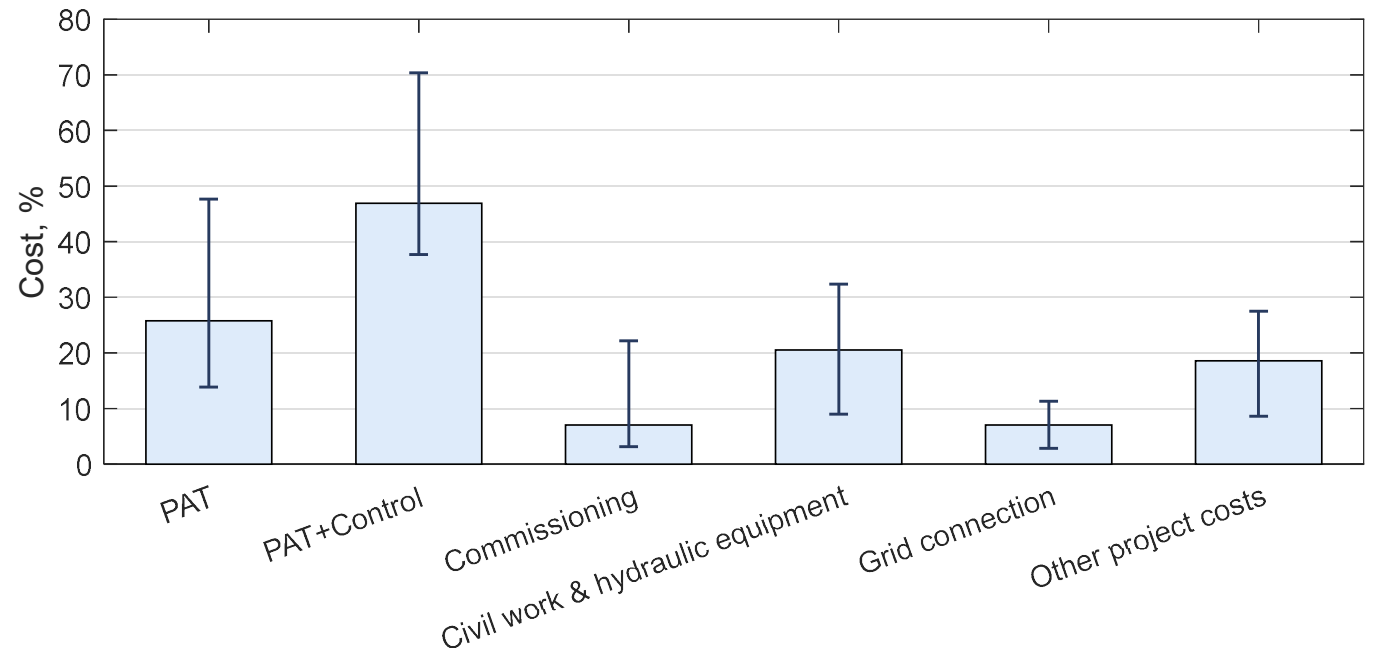

Figure 9. Costs involved in the PAT installation.

The results from Figure 9 showed that across the 9 analysed schemes the purchase of the PAT and generator accounted for $26 \%$ of the total cost of the installation on average, ranging from $14 \%$ to $48 \%$ (see Figure 9). Hence, the results from Equation (8) were divided by a factor of 0.26 in order to achieve 
a realistic estimation of the total expected cost for a PAT-based energy recovery scheme according to its mean operating conditions (Figure 10).

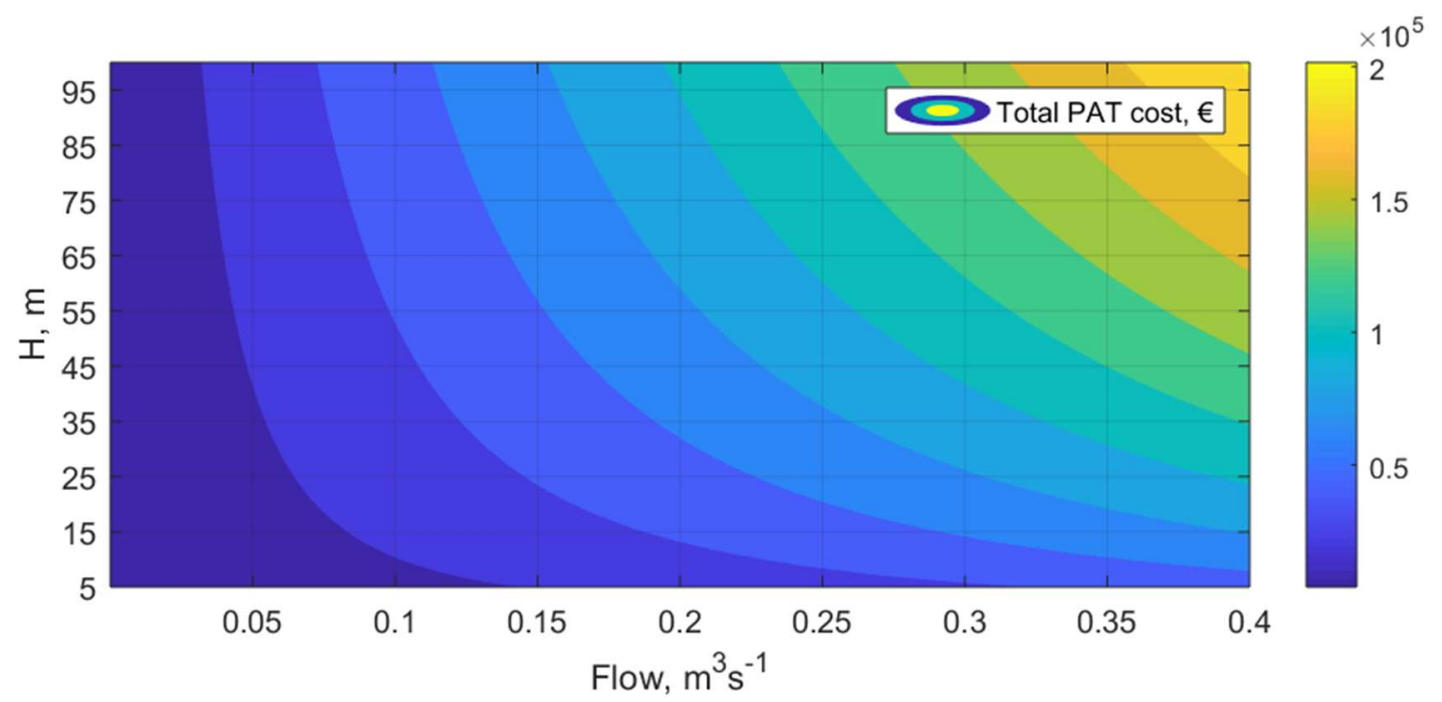

Figure 10. Total PAT cost according to flow and head.

Apart from the turbine and generator, the PAT control devices (with an average cost share of $24 \%$ ) the civil work and hydraulic equipment (involving an average of $21 \%$ of the total cost) and the other project costs (accounting for 19\%) were found to be the most expensive elements in a typical PAT installation.

Considering the PAT cost as $26 \%$ of the total cost, the total PAT installation cost was estimated for the flow range $0.01 \cdot 10^{-3} \mathrm{~m}^{3} \mathrm{~s}^{-1}-0.4 \mathrm{~m}^{3} \mathrm{~s}^{-1}$ and pressure values from $5 \mathrm{~m}$ to $100 \mathrm{~m}$. The average total PAT cost was $72,518 €$, varying from $4035 €$ to $201,662 €$.

When the PAT cost was assumed as $48 \%$ of the total cost, the average PAT installation cost was $39,214 €$, with a minimum cost of $2182 €$ for the lowest values of flow and pressure, and a maximum cost of $109,050 €$. Taking the PAT cost as the $14 \%$ of the total cost, instead, the average total cost was $134,288 €$, varying from $7473 €$ to $373,436 €$.

\subsection{Determination of the Most Feasible Pressure Reduction Device, PRV or PAT, in the Case Studies}

For case study 1 , only average flow and head data were available. Hence, the generated power was determined considering that the average values matched with the flow and head of the PAT at the BEP. 140 sites out of 156 showed an average power higher than the minimum threshold value $(400 \mathrm{~W}$ ), with an average value of $4338 \mathrm{~W}$, ranging from $460 \mathrm{~W}$ to $31,455 \mathrm{~W}$ (see Table 2). As for the total installation cost, the PRV cost was related to the pipe diameter while the PAT cost varied according to the generated power (see Figure 11).

Table 2. PRV/ PAT analysis in case study 1.

\begin{tabular}{|c|c|c|c|c|c|c|c|c|c|c|c|}
\hline & \multirow[t]{2}{*}{$\begin{array}{c}\text { Power, } \\
\text { kW }\end{array}$} & \multirow[t]{2}{*}{$\begin{array}{c}\text { Total PRV } \\
\text { Cost, } €\end{array}$} & \multicolumn{3}{|c|}{ Total PAT Cost, $€$} & \multicolumn{3}{|c|}{ PAT NPV, $€$} & \multicolumn{3}{|c|}{ PAT Payback Period, years } \\
\hline & & & $26 \% 1$ & $48 \%^{2}$ & $14 \%^{3}$ & $26 \% 1$ & $48 \%^{2}$ & $14 \%^{3}$ & $26 \% 1$ & $48 \%^{2}$ & $14 \%^{3}$ \\
\hline Ave. & 4338 & 7236 & 10,397 & 5567 & 20,831 & 57,960 & 61,489 & 59,163 & 4 & 3 & 6 \\
\hline Max. & 31,455 & 32,909 & 60,770 & 32,862 & 112,534 & 451,467 & 467,421 & 421,875 & 10 & 7 & 10 \\
\hline Min. & 460 & 5284 & 4761 & 2575 & 9097 & 2695 & 4197 & 5079 & 2 & 2 & 3 \\
\hline
\end{tabular}

${ }^{1}$ Considering the PAT cost as $26 \%$ of the total cost. ${ }^{2}$ PAT cost as $48 \%$ of the total cost. ${ }^{3}$ PAT cost as $14 \%$ of the total cost. 


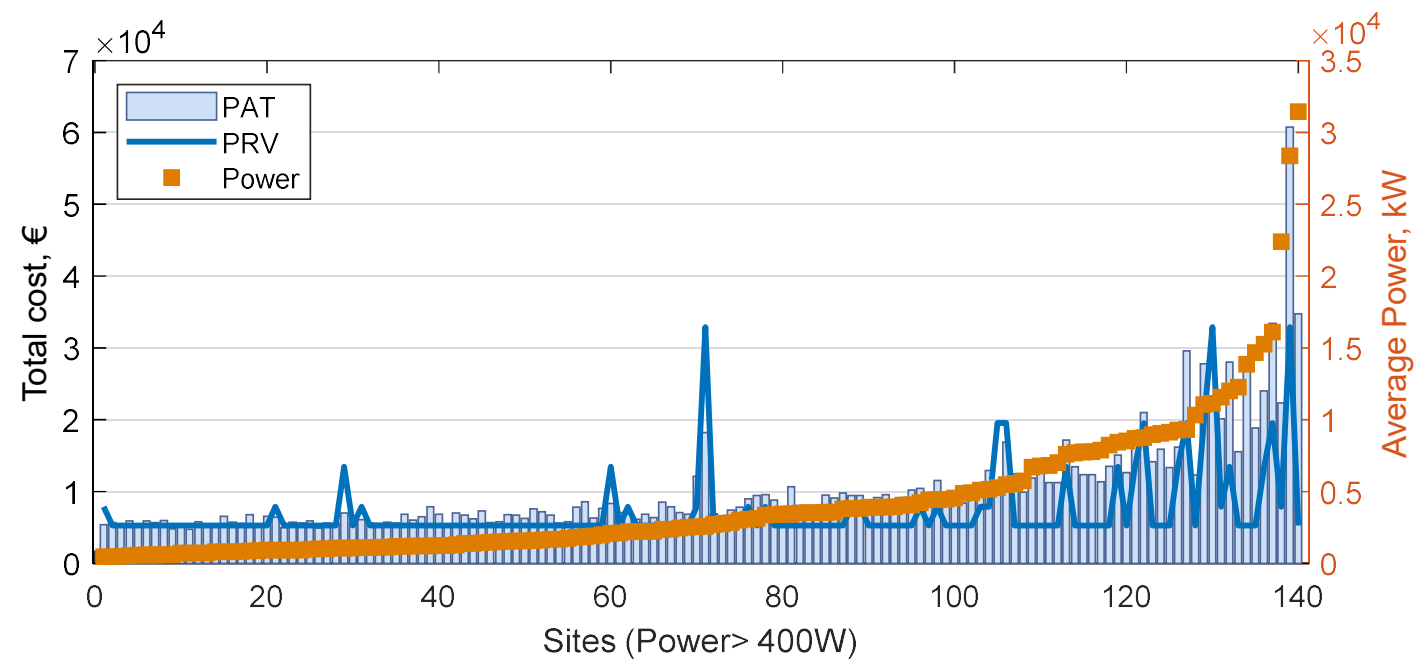

Figure 11. PAT vs. PRV total cost according to the average power at the evaluated sites.

Considering in this case the average total cost of both PRV and PAT, the PRV was the less expensive option in the majority of the sites, with an average total cost of $7236 €$ (see Table 2). In only 15 sites $(10 \%)$ the PAT showed lower capital costs. Analysing these sites, the PAT total cost was slightly cheaper in 6 sites with a $150 \mathrm{~mm}$ diameter and power lower than $1 \mathrm{~kW}$. When the generated power was higher the PRV was the best option considering this diameter. As for the $200 \mathrm{~mm}$ diameters, the PAT was the best option in 3 sites with an average power lower than $2300 \mathrm{~W}$. When the generated power at the sites with a $200 \mathrm{~mm}$ diameter was higher, the PRV was cheaper. A similar tendency was found for pipes of 250, 300 and $400 \mathrm{~mm}$. The lower the generated power the higher the probability that the PAT would be less expensive (see Figure 11).

As for the economic analysis in case study 1, only the energy cost saving was estimated since information about the effects of the PRV performance on nodes pressure was not available. The NPV was determined considering the energy that could be generated in each evaluated site during the PAT lifespan (15 years). Considering that the PAT cost was $26 \%$ of the total cost, the NPV showed positive values in all the 140 sites. The estimated average NPV was $57,960 €$, ranging from $2695 €$ to $451,467 €$ (see Figure 12). The average payback period was 4 years (see Table 2). Under this assumption, three sites showed payback periods higher than the threshold established (see Figure 13).

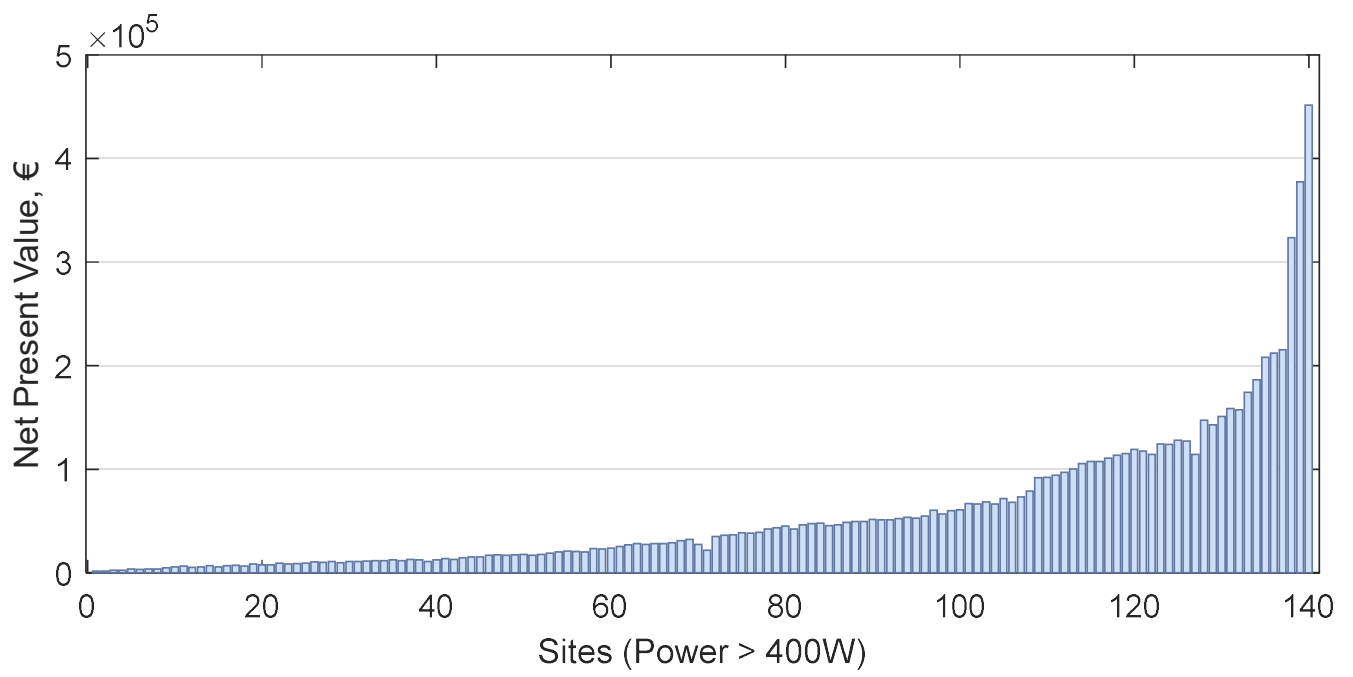

Figure 12. Net present value in the evaluated sites considering that the PAT represents $26 \%$ of the total installation cost. 


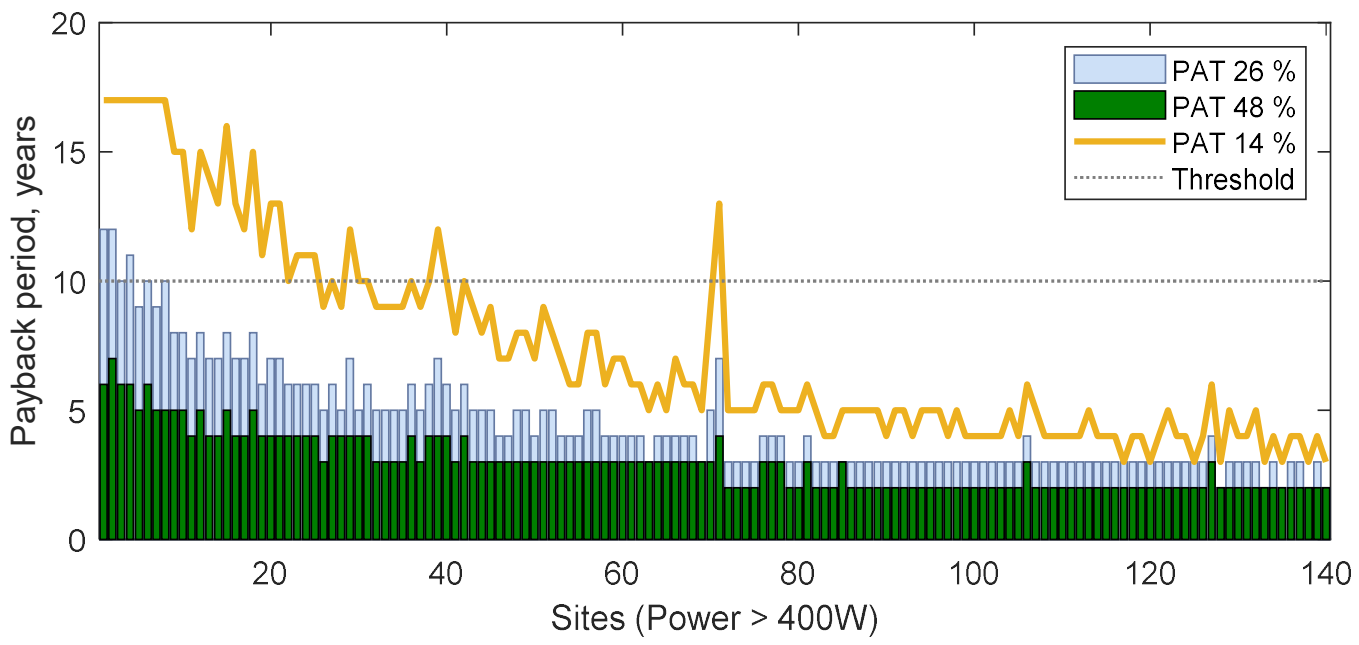

Figure 13. Payback period in the evaluated sites.

When the PAT cost was considered as $14 \%$ of the total cost, 113 out of the 140 sites with power higher than $400 \mathrm{~W}$ showed a payback period lower than 10 years, with an average payback period of 6 years (see Figure 13). As for the NPV, under this assumption the average value was 59,163€, varying from $5079 €$ to $421,875 €$ (see Table 2). Finally, when the PAT cost was assumed as $48 \%$ of the total cost, the payback period was lower than 10 years in all 140 sites with average power higher than $400 \mathrm{~W}$ (see Figure 13), showing an average payback period of 3 year. In this case, the average NPV was $61,489 €$ with a minimum and a maximum value of $4197 €$ and $467,421 €$ (see Table 2). Considering the evaluated sites in case study 1 , the PAT installation costs could be even lower since a current PRV is already operating, making the PAT installation as a retro-fit, more feasible.

For case study 2, the replacement of the three PRVs with PATs would involve powers at the BEP of $1223 \mathrm{~W}, 1533 \mathrm{~W}$ and $457 \mathrm{~W}$ (see Table 3). As for the total installation cost, the PRV showed the lowest values in the majority of the cases. The PAT installation cost was only lower at site 1 , with a diameter of $150 \mathrm{~mm}$, when the PAT cost was assumed as the $48 \%$ of the PAT total cost. The average installation cost ranged from $3009 €$ to $5284 €$ when the PRV was considered and from $5323 €$ to $6268 €$ for the PAT installation.

Table 3. PRV/ PAT analysis in Ballinabranna Group Water Scheme (BGWS).

\begin{tabular}{|c|c|c|c|c|c|c|}
\hline \multirow[b]{2}{*}{ Site Number } & \multicolumn{3}{|c|}{ PRV } & \multicolumn{3}{|c|}{ PAT } \\
\hline & 1 & 2 & 3 & 1 & 2 & 3 \\
\hline Diameter, $\mathrm{mm}$ & 150 & 100 & 100 & 150 & 100 & 100 \\
\hline Power BEP, W & & & & 1223 & 1533 & 457 \\
\hline Energy, kWh year ${ }^{-1}$ & & & & 7346 & 9203 & 2744 \\
\hline Ave cost, $€$ & 5284 & 3009 & 3009 & 5919 & 6268 & 5323 \\
\hline Min cost, $€$ & 3574 & 2303 & 2303 & 3201 & 3390 & 2879 \\
\hline Max cost, $€$ & 7074 & 4067 & 4067 & 10,984 & 11,633 & 9879 \\
\hline Water saving, $\mathrm{m}^{3}$ year $^{-1}$ & 15,559 & 15,559 & 15,559 & 15,559 & 15,559 & 15,559 \\
\hline Water cost saving, $€$ year $^{-1}$ & 4668 & 4668 & 4668 & 4668 & 4668 & 4668 \\
\hline Energy cost saving, $€$ year $^{-1}$ & & & & 1249 & 1565 & 466 \\
\hline Payback period, year & 3.0 & 2.0 & 2.0 & 3.0 & 3.0 & 3.0 \\
\hline NPV, $€$ & 43,164 & 45,440 & 45,440 & 55,493 & 58,420 & 47,967 \\
\hline NPV/Water saving, $€ \mathrm{~m}^{-3}$ & 0.18 & 0.19 & 0.19 & 0.24 & 0.25 & 0.21 \\
\hline
\end{tabular}

The economic analysis in case study 2 was carried out considering both the energy cost saving and the water saving as a result of the PRV/PAT operation. As initial leakage rate, $80 \%$ of the minimum night-time flow was assumed $[36,58]$. The same pressure drop was considered for the PRVs and the 
PATs. Hence, the water saving and the water cost saving showed the same values for both devices: $15,559 \mathrm{~m}^{3}$ year $^{-1}$ and $4668 €$ year $^{-1}$ per pressure reducing device (see Table 3 ). The operation of the three PATs would involve an annual energy cost saving of $1249 €, 1565 €$ and $466 €$. Thus, the NPV considering the PAT lifespan and the average installation cost showed values of 55,493€, 58,420€ and $47,967 €$ at sites 1, 2 and 3, respectively. This was $29 \%, 29 \%$ and $6 \%$ higher than the estimated NPV considering the average PRV installation cost. The ratio between the NPV and the water leakage that could be saved during the PAT/ PRV lifespan offered values for the PATs of $0.24 € \mathrm{~m}^{-3}, 0.25 € \mathrm{~m}^{-3}$ and $0.21 € \mathrm{~m}^{-3}$, again higher than the estimated values for the PRVs (see Table 3).

Therefore, this work shows that although the required investment for a PRV installation is lower in most cases, the energy and hence, the cost savings that could be achieved by considering a PAT justify its installation. While both devices are equally efficient in terms of leakage reduction, the additional energy cost savings achieved by the PAT performance make its installation as a device to reduce leakage and generate energy more feasible.

\section{Discussion}

PATs are considered to be a cheaper technology compared to traditional turbines for small hydropower energy recovery [26,59]. However, information related to the total PAT cost, also including installation cost, is not easily accessible. Overall, methodologies focused on the use of PATs took into account a PAT cost according to the generated power. Thus, [60] considered an average PAT investment cost of $545 € \mathrm{~kW}^{-1}$ for generated power lower than $10 \mathrm{~kW}$, including the PAT cost and the civil, electrical and electronic equipment. [25] determined the total installation cost considering an average PAT cost related to the generated power of $220 € \mathrm{~kW}^{-1}$ plus two additional costs of $450 €$ and $2500 €$ (associated to piping and grid connection). Other methodologies established the installation cost either as a percentage of the total installation cost or as a cost associated to the generated power. [30] considered the installation cost as $65 \%$ of the total cost, whereas [23] proposed an installation cost of $350 € \mathrm{~kW}^{-1}$.

The methodology presented in this work analysed the installation cost and categories of 9 MHP plants in different countries, thus determining an average installation cost and the range. The installation cost determined in the sites of case study 1 , using the methodology presented in this work compared with previous methodologies, showed higher total PAT costs using the values obtained from the 9 MHP plants. Thus, the average total PAT cost at the sites in case study 1 was $3904 €, 2364 €, 4159 €$ and $4251 €$ applying the methodologies proposed by $[23,25,30,60]$, respectively. These were all considerably lower than the average total value presented in this work, $10,397 €$.

Above all, the model presented here shows that when the total costs and benefits of the installation of PATs or PRVs as pressure reduction devices are compared, the PAT is the more feasible option with greater long term benefits. These greater long term benefits were also consistently found when a sensitivity analysis of the assumed variables was conducted (i.e., using min, average and maximum values for percentage contribution of differing cost components).

\section{Conclusions}

A model to determine the most feasible device, PRV or PAT, considering all the costs involved in a PRV and a PAT installation, as well as the water cost savings associated to leakage reduction, and the energy cost saving related to the PAT operation has been proposed. This work highlights the potential of MHP installations in general and PATs in particular as a tool to improve the sustainability of water distribution networks and reduce electricity costs. The analysis carried out showed that a wider database with the real PAT installation cost would be required to better estimate the feasibility of the installation of these devices. Limitations of the current methodology include: The limited amount of information available on PAT costs at very low powers; the lack of significant amounts of case studies on which to base estimates of civil works and other project costs; and the lack of information on the cost and performance of PAT types other than centrifugal. 
The main finding of the work is that the use of a PRV over a PAT as a pressure reduction tool is not the most economically viable or sustainable option. While installing a PRV reduces leakage and thus energy consumption, it wastes the opportunity to recover electricity in the network. The development of less expensive turbines and/or pump as turbines adapted to work under low flow-head condition will tip the balance toward the installation of these devices even more.

Author Contributions: A.M.N., I.F.G. and D.N. conceived and developed the model; I.F.G. and D.N. performed the simulations and analyzed the results; I.F.G. and D.N. wrote the paper; A.M.N., I.F.G. and D.N. revised and corrected the final document.

Funding: This study was part funded by the ERDF Interreg Ireland-Wales programme 2014-2020 through the Dwr Uisce project.

Conflicts of Interest: The authors declare no conflict of interest.

\section{References}

1. WWAP (United Nations World Water Assessment Programme). The United Nations World Water Development Report 2018: Nature-Based Solutions for Water; WWAP: Paris, France, 2018.

2. Singh, L.K.; Jha, M.K.; Chowdary, V.M. Multi-criteria analysis and GIS modeling for identifying prospective water harvesting and artificial recharge sites for sustainable water supply. J. Clean. Prod. 2017, 142, 1436-1456. [CrossRef]

3. McDonald, R.I.; Weber, K.; Padowski, J.; Flörke, M.; Schneider, C.; Green, P.A.; Gleeson, T.; Eckman, S.; Lehner, B.; Balk, D.; et al. Water on an urban planet: Urbanization and the reach of urban water infrastructure. Glob. Environ. Chang. 2014, 27, 96-105. [CrossRef]

4. European Environment Agency. Use of Freshwater Resources. Available online: https://www.eea.europa.eu/ data-and-maps/indicators/use-of-freshwater-resources-2/assessment-2 (accessed on 24 May 2018).

5. U.S. Energy Information Administration. International Energy Outlook. 2017. Available online: www.eia. gov/ieo (accessed on 24 May 2018).

6. Enerdata. Enerdata World Energy Consumption Statistics. Available online: https://yearbook.enerdata.net/ total-energy/world-consumption-statistics.html (accessed on 14 February 2018).

7. World-Bank. What is Non-Revenue Water? How Can We Reduce It for Better Water Service? Available online: https://blogs.worldbank.org/water/what-non-revenue-water-how-can-we-reduce-it-better-waterservice (accessed on 5 June 2019).

8. Loureiro, D.; Amado, C.; Martins, A.; Vitorino, D.; Mamade, A.; Coelho, S.T. Water distribution systems flow monitoring and anomalous event detection: A practical approach. Urban. Water J. 2016, 13, $242-252$. [CrossRef]

9. Mérida García, A.; Fernández García, I.; Camacho Poyato, E.; Montesinos Barrios, P.; Rodríguez Díaz, J.A. Coupling irrigation scheduling with solar energy production in a smart irrigation management system. J. Clean. Prod. 2018, 175, 670-682. [CrossRef]

10. Kollmann, R.; Neugebauer, G.; Kretschmer, F.; Truger, B.; Kindermann, H.; Stoeglehner, G.; Ertl, T.; Narodoslawsky, M. Renewable energy from wastewater-Practical aspects of integrating a wastewater treatment plant into local energy supply concepts. J. Clean. Prod. 2017, 155, 119-129. [CrossRef]

11. Gupta, A.; Dpt, C.; National, V.; Bokde, N.; Dpt, C.; National, V.; Marathe, D.; Dpt, C.; National, V.; Kulat, K.; et al. Leakage Reduction in Water Distribution Systems with Efficient Placement and Control of Pressure Reducing Valves Using Soft Computing Techniques. Eng. Technol. Appl. Sci. Res. 2017, 7, 1528-1534.

12. Parra, S.; Krause, S.; Krönlein, F.; Günthert, F.W.; Klunke, T. Intelligent pressure management by pumps as turbines in water distribution systems: Results of experimentation. Water Sci. Technol. Water Supply 2017, 6, ws2017154. [CrossRef]

13. Fontana, N.; Giugni, M.; Glielmo, L.; Marini, G.; Zollo, R. Real-Time Control of Pressure for Leakage Reduction in Water Distribution Network: Field Experiments. J. Water Resour. Plan. Manag. 2018, 144, 04017096. [CrossRef]

14. Gallagher, J.; Styles, D.; McNabola, A.; Williams, A.P. Life cycle environmental balance and greenhouse gas mitigation potential of micro-hydropower energy recovery in the water industry. J. Clean. Prod. 2015, 99, 152-159. [CrossRef] 
15. Lydon, T.; Coughlan, P.; McNabola, A. Pressure management and energy recovery in water distribution networks: Development of design and selection methodologies using three pump-as-turbine case studies. Renew. Energy 2017, 114, 1038-1050. [CrossRef]

16. McNabola, A.; Coughlan, P.; Corcoran, L.; Power, C.; Prysor Williams, A.; Harris, I.; Gallagher, J.; Styles, D. Energy recovery in the water industry using micro-hydropower: An opportunity to improve sustainability. Water Policy 2014, 16, 168. [CrossRef]

17. Power, C.; Coughlan, P.; McNabola, A. Microhydropower Energy Recovery at Wastewater-Treatment Plants: Turbine Selection and Optimization. J. Energy Eng. 2017, 143, 04016036. [CrossRef]

18. Gallagher, J.; Harris, I.M.; Packwood, A.J.; McNabola, A.; Williams, A.P. A strategic assessment of micro-hydropower in the UK and Irish water industry: Identifying technical and economic constraints. Renew. Energy 2015, 81, 808-815. [CrossRef]

19. Sinagra, M.; Sammartano, V.; Morreale, G.; Tucciarelli, T. A New Device for Pressure Control and Energy Recovery in Water Distribution Networks. Water 2017, 9, 309. [CrossRef]

20. Samora, I.; Manso, P.; Franca, M.; Schleiss, A.; Ramos, H. Energy Recovery Using Micro-Hydropower Technology in Water Supply Systems: The Case Study of the City of Fribourg. Water 2016, 8, 344. [CrossRef]

21. Sammartano, V.; Sinagra, M.; Filianoti, P.; Tucciarelli, T. A Banki-Michell turbine for in-line water supply systems. J. Hydraul. Res. 2017, 55, 686-694. [CrossRef]

22. Sinagra, M.; Aricò, C.; Tucciarelli, T.; Amato, P.; Fiorino, M.; Sinagra, M.; Aricò, C.; Tucciarelli, T.; Amato, P.; Fiorino, M. Coupled Electric and Hydraulic Control of a PRS Turbine in a Real Transport Water Network. Water 2019, 11, 1194. [CrossRef]

23. Carravetta, A.; del Giudice, G.; Fecarotta, O.; Ramos, H. PAT Design Strategy for Energy Recovery in Water Distribution Networks by Electrical Regulation. Energies 2013, 6, 411-424. [CrossRef]

24. Carravetta, A.; Derakhshan Houreh, S.; Ramos, H.M. Application of PAT Technology; Springer International Publishing: Berlin/Heidelberg, Germany, 2018; pp. 189-218.

25. Fecarotta, O.; McNabola, A. Optimal Location of Pump as Turbines (PATs) in Water Distribution Networks to Recover Energy and Reduce Leakage. Water Resour. Manag. 2017, 31, 5043-5059. [CrossRef]

26. Novara, D.; Carravetta, A.; Derakhshan, S.; McNabola, A.; Ramos, H.M. A Cost model for Pumps as Turbines and a comparison of design strategies for their use as energy recovery devices in Water Supply Systems. In Proceedings of the 10th International Conference on Energy Efficiency in Motor Driven Systems (EEMODS'17), Rome Italy, 6-8 September 2017.

27. Giugni, M.; Fontana, N.; Ranucci, A. Optimal Location of PRVs and Turbines in Water Distribution Systems. J. Water Resour. Plan. Manag. 2014, 140, 1-6. [CrossRef]

28. Tricarico, C.; Morley, M.S.; Gargano, R.; Kapelan, Z.; Savić, D.; Santopietro, S.; Granata, F.; de Marinis, G. Optimal energy recovery by means of pumps as turbines (PATs) for improved WDS management. Water Sci. Technol. Water Supply 2018, 184, 1365-1374. [CrossRef]

29. Pérez-Sánchez, M.; Sánchez-Romero, F.; Ramos, H.; López-Jiménez, P.A. Optimization Strategy for Improving the Energy Efficiency of Irrigation Systems by Micro Hydropower: Practical Application. Water 2017, 9, 799. [CrossRef]

30. García Morillo, J.; McNabola, A.; Camacho, E.; Montesinos, P.; Rodríguez Díaz, J.A. Hydro-power energy recovery in pressurized irrigation networks: A case study of an Irrigation District in the South of Spain. Agric. Water Manag. 2018, 204, 17-27. [CrossRef]

31. Fecarotta, O.; Aricò, C.; Carravetta, A.; Martino, R.; Ramos, H.M. Hydropower Potential in Water Distribution Networks: Pressure Control by PATs. Water Resour. Manag. 2015, 29, 699-714. [CrossRef]

32. Patelis, M.; Kanakoudis, V.; Gonelas, K. Pressure Management and Energy Recovery Capabilities Using PATs. Procedia Eng. 2016, 162, 503-510. [CrossRef]

33. The Public Spending Code. Ireland Department of Public Expenditure and Reform E-Technical References. Available online: http://publicspendingcode.per.gov.ie/technical-references/ (accessed on 14 May 2018).

34. Araujo, L.S.; Ramos, H.; Coelho, S.T. Pressure Control for Leakage Minimisation in Water Distribution Systems Management. Water Resour. Manag. 2006, 20, 133-149. [CrossRef]

35. Rossman, L.A. EPANET 2 Users Manual EPA/600/R-00/57; U.S. Environmental Protection Agency: Cincinnati, $\mathrm{OH}, \mathrm{USA}, 2000$.

36. Araujo, L.S.; Ramos, H.; Coelho, S.T. Estimation of distributed pressure-dependent leakage and consumer demand inwater supply networks. In Advance in Water Supply Management; CRC Press: London, UK, 2003. 
37. Fernández García, I.; Ferras, D.; McNabola, A. Potential of energy recovery and water saving using microhydropower in rural water distribution networks. J. Water Resour. Plan. Manag. 2019, 145, 1-11. [CrossRef]

38. The MathWorks Inc. MATLAB Version R2016b; The MathWorks Inc.: Natick, MA, USA, 2016.

39. SEAI. Electricity \& Gas Prices in Ireland. 1st Semester (January-June) 2017. Available online: https: //www.seai.ie/resources/publications/Electricity_Gas_Prices_January_June_2017 (accessed on 10 May 2018).

40. Carravetta, A.; Fecarotta, O.; Ramos, H.M. A new low-cost installation scheme of PATs for pico-hydropower to recover energy in residential areas. Renew. Energy 2018, 125, 1003-1014. [CrossRef]

41. Fecarotta, O.; Ramos, H.M.; Derakhshan, S.; Del Giudice, G.; Carravetta, A. Fine Tuning a PAT Hydropower Plant in a Water Supply Network to Improve System Effectiveness. J. Water Resour. Plan. Manag. 2018, 144, 04018038. [CrossRef]

42. Novara, D.; McNabola, A. A model for the extrapolation of the characteristic curves of Pumps as Turbines from a datum Best Efficiency Point. Energy Convers. Manag. 2018, 174, 1-7. [CrossRef]

43. Grancho Ferreira, A.R. Energy Recovery in Water Distribution Networks towards Smart Water Grids. Master's Thesis, University of Lisbon, Lisbon, Portugal, 2017.

44. BERMAD PRV cost. Personal Communication, 2018.

45. CLA-VAL PRV cost. Personal Communication, 2018.

46. WATTs PRV cost. Personal Communication, 2018.

47. Flomatic PRV cost. Personal Communication, 2018.

48. AVK PRV cost. Personal Communication, 2018.

49. CSA PRV cost. Personal Communication, 2018.

50. Valves-Online PRV cost. Personal Communication, 2018.

51. Talis PRV cost. Personal Communication, 2018.

52. TRAGSA Tarifas 2015 Para Encomiendas Sujetas a Impuestos. 2015. Available online: https://www.tragsa.es/es/grupo-tragsa/regimen-juridico/Documents/ACTUALIZACI\%C3\%93N\% 20TARIFAS\%20AGOSTO/Tarifas\%202015\%20para\%20encomiendas\%20sujetas\%20a\%20impuestos.pdf (accessed on 20 June 2019).

53. Novara, D.; Carravetta, A.; McNabola, A.; Ramos, H.M. Cost model for Pumps As Turbines in run-off-river and in-pipe micro-hydropower applications. J. Water Resour. Plan. Manag. 2019, 145, 04019012. [CrossRef]

54. Ogayar, B.; Vidal, P.G. Cost determination of the electro-mechanical equipment of a small hydro-power plant. Renew. Energy 2009, 34, 6-13. [CrossRef]

55. Kramer, M.; Terheiden, K.; Wieprecht, S. Pumps as turbines for efficient energy recovery in water supply networks. Renew. Energy 2018, 122, 17-25. [CrossRef]

56. Livramento, J.M. Central micro-hídrica incorporada em adutora. Master's Thesis, Faculdade de Ciências e Tecnologia, Universidade do Algarve, Faro, Portugal, 2013.

57. Lledó, J. Tecnoturbines. Powering Water 2016. Available online: https://www.mapa.gob.es/images/es/ttcenter_tcm30-131554.pdf (accessed on 20 June 2019).

58. Alkasseh, J.M.A.; Adlan, M.N.; Abustan, I.; Aziz, H.A.; Hanif, A.B.M. Applying Minimum Night Flow to Estimate Water Loss Using Statistical Modeling: A Case Study in Kinta Valley, Malaysia. Water Resour. Manag. 2013, 27, 1439-1455. [CrossRef]

59. Ramos, H.; Borga, A. Pumps as turbines: An unconventional solution to energy production. Urban. Water 1999, 1, 261-263. [CrossRef]

60. Pérez-Sánchez, M.; Sánchez-Romero, F.J.; López-Jiménez, P.A.; Ramos, H.M. PATs selection towards sustainability in irrigation networks: Simulated annealing as a water management tool. Renew. Energy 2018, 116, 234-249. [CrossRef]

(C) 2019 by the authors. Licensee MDPI, Basel, Switzerland. This article is an open access article distributed under the terms and conditions of the Creative Commons Attribution (CC BY) license (http://creativecommons.org/licenses/by/4.0/). 